\title{
Dark Green Islands in Plant Virus Infection are the Result of Posttranscriptional Gene Silencing
}

\author{
Carolyn J. Moore, ${ }^{1,2}$ Paul W. Sutherland, ${ }^{1}$ Richard L. S. Forster, ${ }^{1}$ Richard C. Gardner, ${ }^{2}$ \\ and Robin M. MacDiarmid ${ }^{1}$ \\ ${ }^{1}$ The Horticulture and Food Research Institute of New Zealand Limited, Private Bag 92169, Auckland, New \\ Zealand; ${ }^{2}$ University of Auckland, Private Bag 92019, Auckland, New Zealand \\ Submitted 15 January 2001; Accepted 6 April 2001.
}

Dark green islands (DGIs) are a common symptom of plants systemically infected with a mosaic virus. DGIs are clusters of green leaf cells that are free of virus but surrounded by yellow, virus-infected tissue. We report here on two lines of evidence showing that DGIs are caused by posttranscriptional gene silencing (PTGS). First, transcripts of a transgene derived from the coat protein of Tamarillo mosaic potyvirus (TaMV) were reduced in DGIs relative to adjacent yellow tissues when the plants were infected with TaMV. Second, nontransgenic plants coinfected with TaMV and a heterologous virus vector carrying TaMV sequences showed reduced titers of the vector in DGIs compared with surrounding tissues. DGIs also were compared with recovered tissue at the top of transgenic plants because recovery has been shown previously to involve PTGS. Cytological analysis of the cells at the junction between recovered and infected tissue was undertaken. The interface between recovered and infected cells had very similar features to that surrounding DGIs. We conclude that DGIs and recovery are related phenomena, differing in their ability to amplify or transport the silencing signal.

Additional keyword: white clover mosaic virus.

Dark green islands (DGIs) have been the focus of morphological and cytological analysis, even before the nature of viruses was known (Allard 1914). DGIs occur when a mosaic virus systemically infects a plant and gives rise to symptoms that include chlorosis of the leaves surrounding discrete regions of dark-green tissue. Cells within DGIs are free of viral RNA and proteins (Atkinson and Matthews 1970). These cells also demonstrate resistance to superinfection by the original and closely related viruses but are susceptible to infection by unrelated viruses (Fulton 1951). Tamarillo mosaic virus (TaMV), a strain of Potato virus A (Rajamäki et al. 1998), produces DGIs upon infection of host plants. TaMV is a mo-

Corresponding author: R. C. Gardner, E-mail: r.gardner@auckland.ac.nz

Current address of R. L. S. Forster: Genesis Research and Development, P.O. Box 50, Auckland, New Zealand.

Current address of R. M. MacDiarmid: University of California, Berkeley 94720-3102, U.S.A. nopartite, positive-strand RNA virus belonging to the Potyviridae spp. (Eagles et al. 1990). A single open reading frame codes for a $346-\mathrm{kDa}$ polyprotein that is processed into mature viral proteins (Dougherty et al. 1988). TaMV was originally isolated from tamarillo plants (Cyphomandra betacea) (Mossop 1977) but systemically infects Nicotiana benthamiana to give mosaic symptoms comparable to those observed in tamarillo (Fig. 1).

Cytological and morphological studies on DGIs have been performed with Turnip yellow mosaic virus (TYMV) and Tobacco mosaic virus infections of Brassica rapa and Nicotiana tabacum, respectively (Matthews 1991). These studies reveal that DGI tissue has a phenotype similar to healthy tissue and DGI formation is a developmentally predictable event that occurs at random sites across a leaf. Typically, DGIs encompass more than one cell layer and contain more cells than can be accounted for if a DGI was the product of a single cell's division. These factors led to the proposal that a "diffusible factor" was responsible for the formation and maintenance of the islands (Atkinson and Matthews 1970).

Plants containing viral transgenes can sometimes be triggered into producing recovered tissue by infection with the corresponding virus (Dougherty et al. 1994). Recovery is typified by the formation of noninfected tissue in the developing leaves at the top of a virus-infected plant. Recovered tissues such as DGIs are free of viral RNA and proteins and are resistant to superinfection by the same virus but susceptible to infection by unrelated viruses (Dougherty et al. 1994; Guo and Garcia 1997; Pang et al. 2000). In addition, recovered tissue has been shown to undergo posttranscriptional degradation of the viral and the transgene RNA (Dougherty et al. 1994; Guo and Garcia 1997).

Posttranscriptional gene silencing (PTGS) was recognized initially in plants (Lindbo and Dougherty 1992; Napoli et al. 1990; Van der Krol et al. 1990), but similar phenomena have since been observed in fungi (Meyer 1996) and animals (PalBhadra et al. 1997; Ruiz et al. 1998a; Tuschl et al. 1999; Wianny and Zernicka-Goetz 2000). Known as "quelling" and "RNA-interference" respectively, these numerous examples of PTGS-like events across many species suggest that PTGS is a general phenomenon of eukaryotes (Fagard et al. 2000).

PTGS is characterized by the cytoplasmic degradation of RNA in a sequence-specific manner and the presence of small 21 - to 25-nucleotide fragments of the targeted sequence 
(Waterhouse et al. 1999). This precisely targeted degradation is probably the consequence of a natural defense system aimed at reducing aberrant or foreign RNAs (Baulcombe 1999; Jorgensen et al. 1998). In plants, it has been proposed that the primary functions of PTGS are defense against viral infection (Ratcliff et al. 1997) and transposon-induced irregularities in gene expression (Ketting et al. 1999).

Here, we investigate the hypothesis that DGIs are the result of PTGS. We show that recovered tissue encompasses more than one cell layer and that the boundary between recovered and infected tissues is similar to that described previously for DGIs (Atkinson and Matthews 1970). We also present evidence that DGIs are undergoing PTGS. In transgenic plants, degradation of a viral transgene occurs in DGIs but not in infected tissue. A heterologous viral vector is used to show that there is cytoplasmic targeting of specific viral RNA sequences in the DGIs of nontransgenic plants. Finally, we propose that the motility of the silencing signal is limited in most nontransgenic plants to cell-to-cell movement. The presence of a viral transgene permits the signal to move systemically, however, resulting in recovery after challenge with the cognate virus.

\section{RESULTS}

\section{DGI formation precedes the development} of the recovery phenotype in transgenic plants.

A series of transgenic $N$. benthamiana plants containing the TaMV coat protein $(\mathrm{CP})$ coding sequence were generated. One line of plants (PS26) was initially susceptible to infection by TaMV before developing recovered, virus-free tissue at the top of the plant. Infection of fourth generation $\left(\mathrm{T}_{4}\right)$ plants from the PS26 line consistently produced the characteristic mosaic symptoms of viral infection, followed by recovery. The progression of TaMV symptoms to recovery was sequential and predictable under controlled conditions. At 3 weeks postinoculation, developing leaves showed mosaic symptoms, including DGIs (Fig. 1B). During the following week, the newly emerged leaves showed a bizonal appearance, showing infected and recovered tissue on a single leaf (Fig. 1C). In these bizonal leaves, the chlorotic infected tissue was at the distal end of the leaves, which is the opposite orientation from leaves that undergo a source-sink transition during the normal progression of TaMV infection. Subsequent leaves on recovered plants were completely free of TaMV symptoms and phenotypically identical to uninfected control leaves. No infection ensued when recovered tissue was ground and mechanically inoculated onto indicator plants.

\section{The junction between infected and recovered tissue is clearly defined and encompasses different cell layers.}

Cells in DGIs are phenotypically normal (Atkinson and Matthews 1970), and there is an abrupt transition from infected to uninfected cells that encompasses multiple cell layers (Atkinson and Matthews 1970; Iwanowski 1903). We undertook to determine whether the same was true at the interface between yellow infected tissue and recovered tissue on the bizonal leaves (Fig. 1C). In cytological studies of DGIs, the demarcation between recovered and yellow infected tissues has been assessed by the intensity of toluidine blue staining, when visualized under a light microscope, and chloroplast shape, when seen under light and electron microscopes (Fig. 2) (Chalcroft and Matthews 1966). Toluidine blue is a general, nonspecific stain that stains cell wall components of cells in healthy, recovered, and DGI tissues, making them darker than the walls of cells that are infected virally. The criteria of chloroplast shape and toluidine blue staining were used with a light microscope to produce cell maps of the macroscopic interface between infected and recovered tissue (Fig. 3 , cell shapes and positions). These maps were used as a guide for electron microscopy determination of the presence or absence of viral particles or inclusion bodies (Fig. 2) in each cell (Fig. 3, shaded or white cells, respectively). These two flanking sampled sections resulted in approximately $1 \%$ of the total volume from each cell being examined for viral particles and inclusion bodies under an electron microscope. This data was then transferred to the cell map to create a pictorial representation of where the virus was detected (Fig. 3). Cells within recovered tissue contained no visible viral particles or inclusion bodies. In contrast, many cells within the immediately adjacent symptomatic tissue contained numerous viral particles (Fig. 3). The switch from infection to recovery was
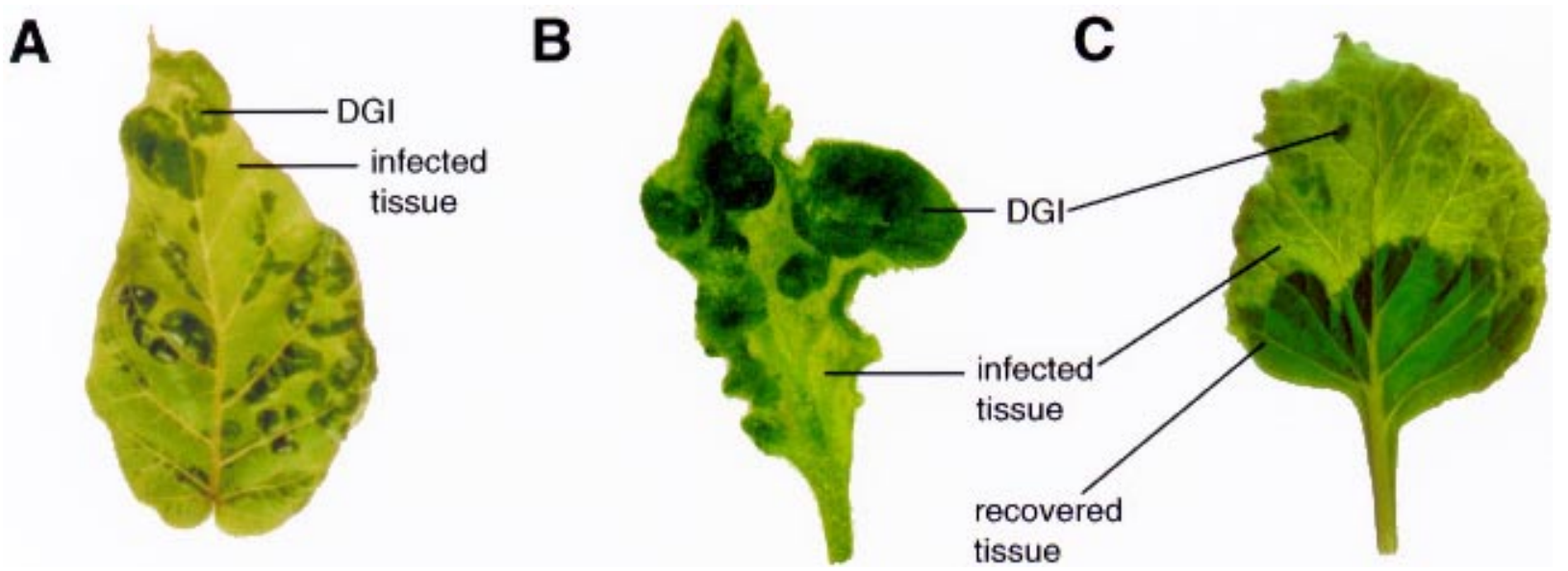

Fig. 1. Characteristic symptoms of Tamarillo mosaic potyvirus (TaMV) infection. A, Tamarillo leaf displaying the prominent dark green islands (DGIs), which led to the isolation of the virus. Leaf length is $25 \mathrm{~cm}$. B, Wild-type Nicotiana benthamiana leaf infected with TaMV. Leaf length is $5 \mathrm{~cm}$. C, PS26 transgenic $N$. benthamiana leaf showing DGIs and the beginning of the recovery phenotype in one leaf (bizonal). Leaf length is $7 \mathrm{~cm}$. 
abrupt, occurring between adjoining cells with no indication of a gradual transition. This demarcation was apparent throughout all layers of the leaf. Western analysis confirmed the lack of viral protein in the recovered tissue compared with its presence in surrounding tissue (data not shown). It has been observed previously that the differentiation of cells in virus-containing regions is not as complete as for those in noninfected or DGI tissue (Dickson 1922; Goldstein 1926; Iwanowski 1903). We found that palisade cells in recovered tissue generally were vertically elongated (Fig. 3, right side of dotted lines), whereas those in the TaMV-containing tissue (Fig. 3, left side of dotted lines) tend to be more circular (Fig. 3 and data not shown).

\section{Viral and transgene RNAs are specifically targeted for degradation in DGIs.}

Northern analysis was performed to assess viral titer and transcript levels produced by the transgene (Fig. 4A) in PS26 plants producing leaves with DGIs. Figure 4B shows an example of Northern analysis, demonstrating that virus accumulation was reduced in DGIs compared with adjacent yellow tissue (Fig. 4B, TaMV CP probe). Northern analyses on 72 samples from different DGIs showed consistent reductions of virus titer with at least a 100-fold decrease in virus accumulation in the majority of cases, as quantified by phosphorimage
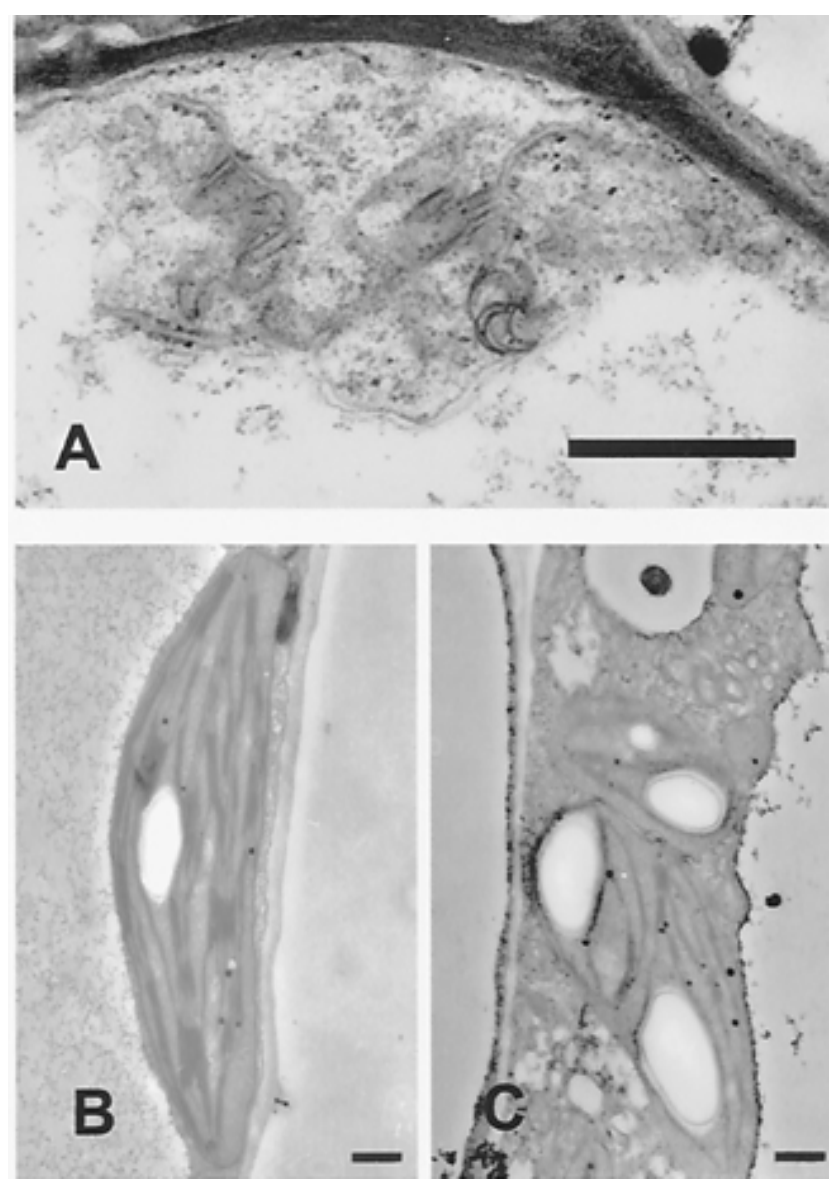

Fig. 2. Electron micrographs of leaf cells of Nicotiana benthamiana. A, Tamarillo mosaic potyvirus (TaMV) cytoplasmic inclusion bodies within a cell. B, Chloroplast in a healthy cell. $\mathbf{C}$, Chloroplast in a cell infected with TaMV. Bar $=500 \mathrm{~nm}$. analysis or visual comparison of autoradiographs (Fig. 4C). In no case did we observe virus accumulation in DGIs to levels equivalent to those in adjacent yellow tissue. Similar reductions in viral titer were found in a sample of 21 DGIs from nontransgenic plants infected with TaMV (Fig. 4C).

The viral RNA observed in some DGI samples may have originated from contamination of the DGI tissue with adjacent infected tissue. This contamination could have been the result of the small size of the DGIs or that DGI margins are not always distributed homogeneously throughout all the cell layers (Atkinson and Matthews 1970; Holmes 1928).

The 3' mannopine synthase (MAS) probe was used for Northern analysis to determine the accumulation of transgene transcripts in DGIs and the surrounding yellow tissue (Fig. 4B, MAS probe). Six DGIs were analyzed, and none contained detectable levels of transgene RNA, whereas transcript was visible in all of the adjacent yellow tissue sampled. Together, these data demonstrate that the accumulation of virus and transgene RNA is reduced significantly in DGIs compared with surrounding tissue.

\section{DGIs in nontransgenic plants}

target cytoplasmic CP RNA sequences for degradation.

For two potyviruses, nuclear run-on experiments have been used to show that the recovery of transgenic plants results from PTGS events (Dougherty et al. 1994; Guo and Garcia 1997). Similar experiments have shown that PTGS is operat-
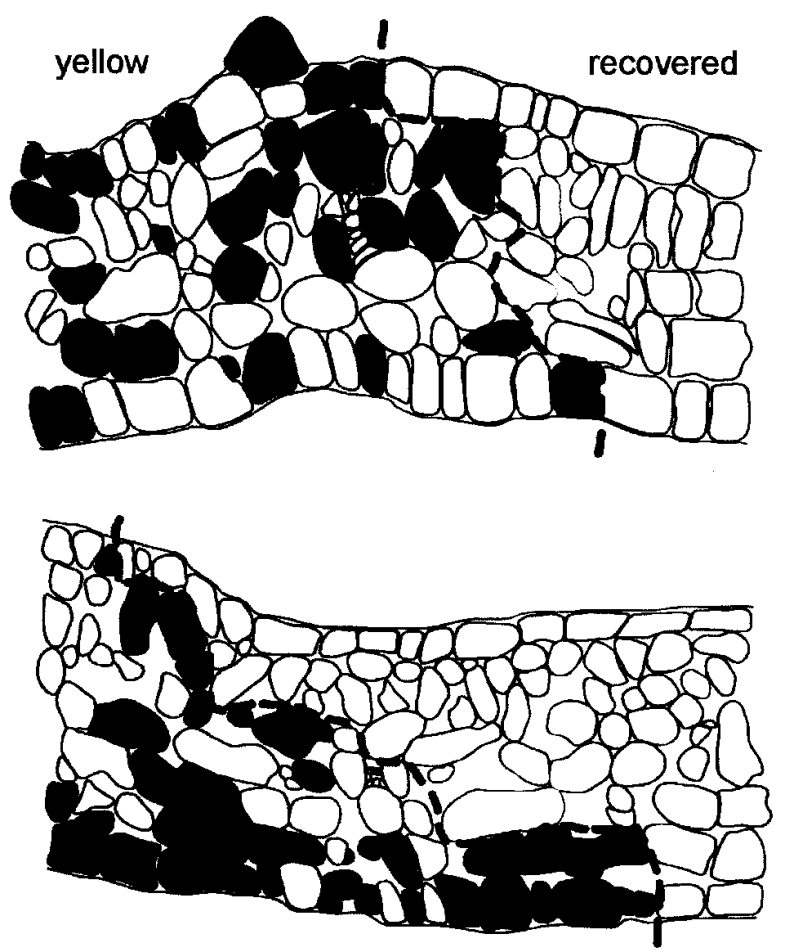

Fig. 3. Map of the viral content of the cells at the macroscopic junction between green recovered tissue and yellow tissue in two bizonal leaves. Cell maps were drawn from light microscopy images, and the viral content of each cell was determined by examining two flanking sections under an electron microscope. This assay directly surveyed approximately $1 \%$ of the volume of each cell. Black cells indicate where viral particles were observed. Dotted lines indicate the visible interface between the infected yellow tissue (left) and green recovered tissue. 
ing in other lines of plants that are transgenic for the TaMV $\mathrm{CP}$ and that undergo recovery (E. Balmori, personal communication). Similar experiments in DGIs were not possible because the tissue was too limited. An alternative approach was used to demonstrate PTGS by Baulcombe and coworkers on the basis of heterologous viral vectors to deliver target RNA (Ruiz et al. 1998b). We used a vector based on an infectious clone of White clover mosaic potexvirus (WCIMV) (Beck et al. 1990). WCIMV has a replication cycle that is limited to the cytoplasm, systemically infects $N$. benthamiana without

\section{A}

\begin{tabular}{|l|l|l|l|}
\hline CaMV D35S & STNV 5' UTR & TAMV CP $\rightarrow$ & MAS 3' \\
\hline
\end{tabular}

B
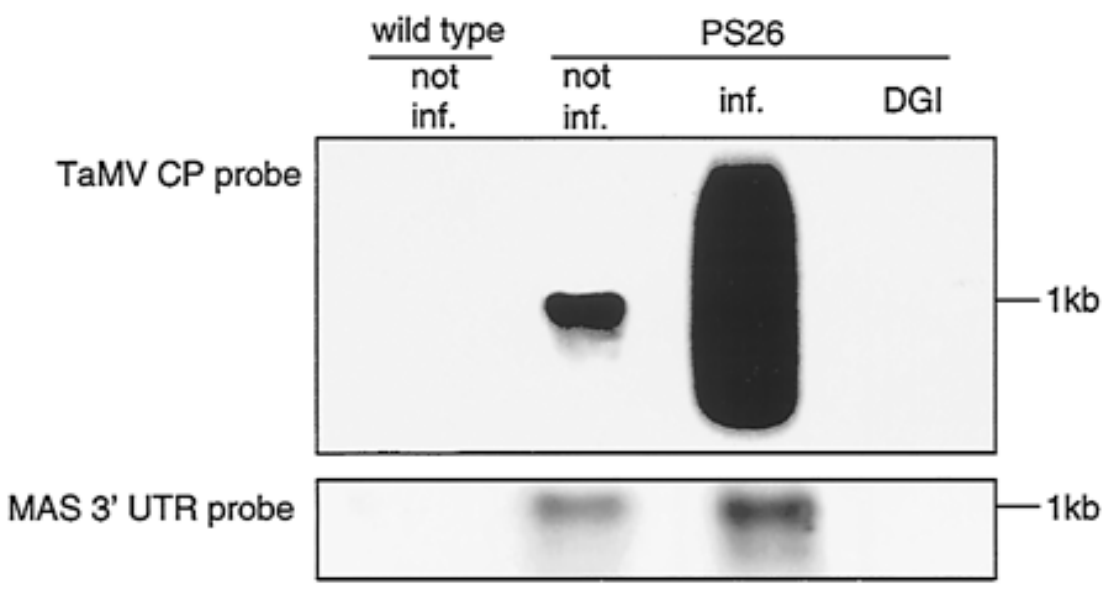

ssRuBP probe $\longrightarrow \longrightarrow 50 \mathrm{bp}$

\section{Summary of Northern analysis of DGls}

\begin{tabular}{|l|c|c|}
\multicolumn{1}{c}{ PS26 plants } & Wild type plants \\
\hline $\begin{array}{l}\text { DGls with less than 1\% of the } \\
\text { viral content of adjacent yellow } \\
\text { tissue }\end{array}$ & $\begin{array}{c}37 \text { DGls } \\
(51 \%)\end{array}$ & $\begin{array}{c}14 \text { DGls } \\
(67 \%)\end{array}$ \\
\hline $\begin{array}{l}\text { DGls with 1-10\% of the viral } \\
\text { content of adjacent yellow } \\
\text { tissue }\end{array}$ & $\begin{array}{c}27 \text { DGls } \\
(38 \%)\end{array}$ & $\begin{array}{c}4 \mathrm{DGls} \\
(19 \%)\end{array}$ \\
\hline $\begin{array}{l}\text { DGls with 10-50\% of the viral } \\
\text { content of adjacent yellow } \\
\text { tissue }\end{array}$ & $8 \mathrm{DGls}$ & $3 \mathrm{DGls}$ \\
\hline Total surveyed & $(11 \%)$ & $(14 \%)$ \\
\hline
\end{tabular}

Fig. 4. Reduction of Tamarillo mosaic potyvirus (TaMV) RNA and TaMV coat protein (CP) transgene transcript in dark green islands (DGIs). A, Schematic of the transgene present in the PS26 plants. Transgene contains the Cauliflower mosaic virus 35S promoter with a duplicated enhancer region (D35S), the 5' untranslated region (UTR) from satellite tobacco necrosis virus (STNV), mannopine synthase (MAS) 3' UTR, and TaMV CP (34-840 nucleotides of accession no. X54804). The construct was inserted into the binary vector pCGN1558 for plant transformation (McBride and Summerfelt 1990) with Agrobacterium tumefaciens. B, Northern blots of total RNA (three replicate Northern filters were probed as indicated). The TaMV CP probe (upper panel) is predicted to detect the transgene $(1 \mathrm{~kb})$ and the viral genomic RNA (smear from $10 \mathrm{~kb}$ down). The MAS probe (central panel) is transgene specific, and the small subunit of ribulose 1,5-bisphosphate carboxylase (ssRuBP) probe (lower panel) is a loading control. Lane 1: RNA from noninoculated wild-type Nicotiana benthamiana. Lane 2: RNA from noninoculated PS26 plant. Lane 3: RNA from the yellowed portion of a TaMVinfected leaf. Lane 4: RNA from a DGI in the same leaf as the infected tissue in lane 3. C, The intensity of the TaMV CP signal after Northern hybridization was compared between DGIs and the adjacent yellow tissue. The relative intensity of the two bands was estimated by comparing the ratio of the phosphorimager or by visual assessment of band intensities. The DGI (with adjacent yellow tissue) shown in the two right lanes of $\mathbf{B}$ is an example of the most common category of DGIs, namely those with less than $1 \%$ of the viral content of adjacent tissue. 
symptoms, and is unrelated to TaMV at the nucleic acid and amino acid levels. If PTGS was responsible for the DGI phenotype, then the inclusion of a portion of the TaMV CP sequence into WCIMV should result in the exclusion of the chimeric virus from cells able to degrade these TaMV sequences in the cytoplasm. This experimental approach allowed us to sample extremely small DGIs and analyze DGIs in nontransgenic plants.

The TaMV CP was inserted into the WClMV vector $7 \mathrm{~K}^{*}$ to give the WClMV-based construct, WTam (Fig. 5A) (E. Balmori, personal communication), which was designed for replication but not translation of the TaMV CP RNA. In vitro transcription resulted in a viral RNA that was able to systemically infect $N$. benthamiana, was transmissible from plant to plant via sap inoculation, and was asymptomatic. Some loss of the TaMV CP insert from WTam occurred after multiple passages or extended, 3- to 4-month infections (data not shown). The insert was stable in the time period of these experiments, however, as assessed by reverse transcriptionpolymerase chain reaction (RT-PCR) with primers in the WCIMV sequence spanning the TaMV CP region (Fig. 5A). Double infection of WTam and TaMV gave plants infected systemically with both viruses, which displayed the characteristic symptoms of TaMV.

Serial dilution RT-PCR was performed in order to determine whether the inclusion of the TaMV CP sequence prevented replication of WTam in the DGI tissue of wild-type plants. RT-PCR was used in preference to Northern hybridization because it i) is more sensitive in detecting the low viral titers found in DGIs; ii) allows smaller tissue samples to be taken from individual DGIs, giving a decreased possibility of contamination with surrounding infected tissue; and iii) simultaneously detects potential deletions of the TaMV insert in the vector. Control RT-PCRs were carried out with primers to detect the small subunit of ribulose 1,5-bisphosphate carboxylase (ssRuBP) as a measure of the relative amount of RNA present in each sample. Plants coinfected with WCIMV and TaMV were found to contain WCIMV RNA throughout their leaves, including in the DGIs (Fig. 5B). In plants inoculated with WTam and TaMV, however, there was detectable WTam in the yellow tissue but at least 125-fold less in the DGIs (Fig. 5C). Similar results were obtained for all five DGIs tested from each combination of viruses.

The RT-PCR data derived from a TaMV-containing vector virus in wild-type plants are comparable to those derived by Northern analysis of intact TaMV in transgenic and nontransgenic lines. The results demonstrate that the exclusion of TaMV sequences from wild-type DGIs is a cytoplasmically based, sequence-dependent RNA degradation mechanism that is characteristic of PTGS.

\section{DISCUSSION}

\section{DGIs involve PTGS.}

DGIs, small pockets of uninfected virus-resistant cells in leaves of otherwise fully infected plants, have been an enigma since they were first documented (Allard 1914). Dougherty et al. (1994) observed that some transgenic plants could recover from viral infection to produce virus-resistant tissue that was reminiscent of DGIs. The discovery that targeted RNA degradation was occurring in the recovered tissue of transgenic plants (Dougherty et al. 1994) suggested a plausible hypothesis for the phenomenon of DGIs in nontransgenic plants. The results described here provide evidence for cytoplasmically located, sequence-specific degradation of RNA in DGIs. These features are characteristic of PTGS.

Recovered tissue (Fig. 1C) was phenotypically similar to tissue in healthy leaves and to DGIs in infected plants. There were no chloroplast abnormalities and no virus particles present in cells from recovered tissue. In contrast, the adjacent yellow leaf tissue showed increased distortion of the chloroplasts (Fig. 2) and the presence of virus particles in the cytoplasm (Fig. 2). There also was a trend toward reduced elongation of palisade cells (Fig. 3). The junction between recovered and infected tissue showed a clear boundary that encompassed
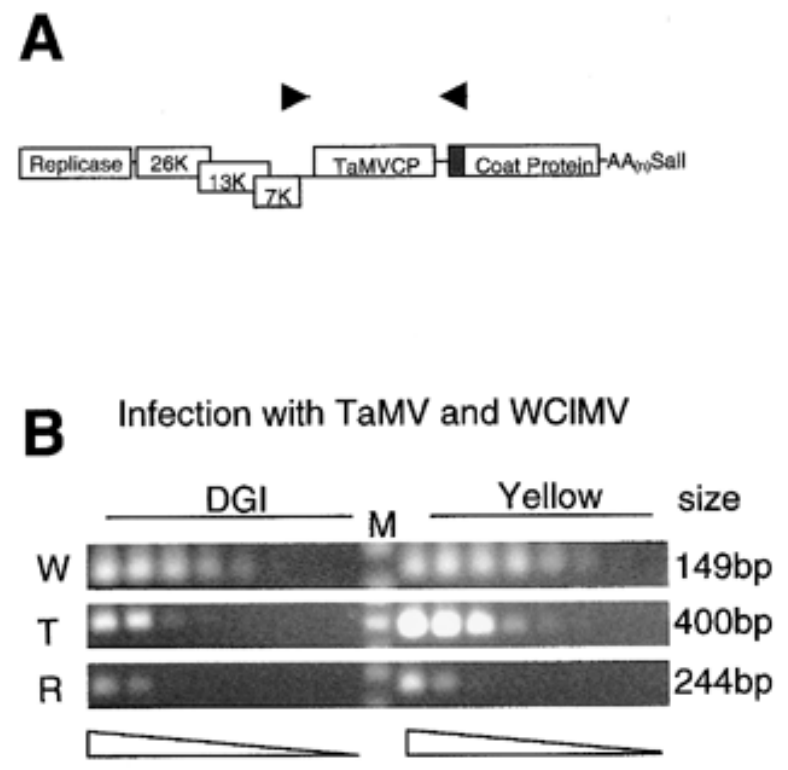

C Infection with TaMV and WTam

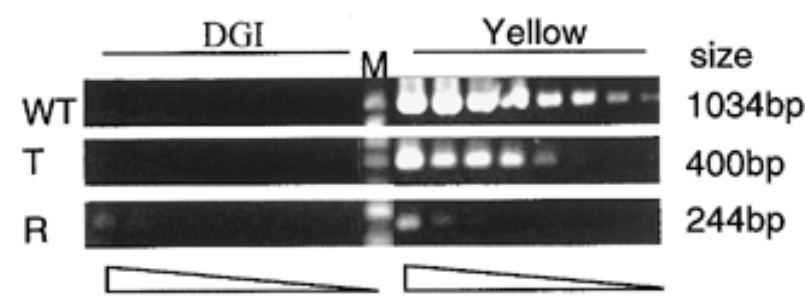

Fig. 5. Reduction of WCIMV-based construct WTam, but not White clover mosaic potexvirus (WCIMV), in Tamarillo mosaic potyvirus (TaMV) dark green islands (DGIs). A, Map of WTam used in this work, which was constructed by E. Balmori. Arrows indicate the placement of primers used in the detection and quantification of WTam and WCIMV. B, Reverse transcription-polymerase chain reaction (RT-PCR) detection of WCIMV and TaMV in DGIs and adjacent yellow tissue. Total RNA was extracted from a DGI and an equivalent area of adjacent yellow tissue. RNA was diluted stepwise through fivefold dilutions and used as the template in a one-step RT-PCR reaction with TaMV (T), WCIMV (W), or a small subunit of ribulose 1,5-bisphosphate carboxylase (R) primers (Table 1). The resulting products (sizes shown on left) were separated by gel electrophoresis. Each set of seven lanes shows the serial dilution of one sample. C, Similar to $\mathbf{B}$ but with tissue from a leaf infected with TaMV and WTam (wild type). $\mathrm{M}=$ molecular weight marker (1-kb Plus Ladder; Life Technologies, Rockville, MD, U.S.A.). 
different cell layers in the leaf. All of these features of recovered tissue are the same as those previously noted for DGIs (Atkinson and Matthews 1970).

We presented two lines of evidence that the mechanism of sequence-specific viral resistance in DGIs involves PTGS. First, DGIs in transgenic plants show a reduction in the steady-state levels of transcript produced by the transgene. Second, in nontransgenic plants, an unrelated virus (WCIMV) was targeted for degradation in DGIs only when it carried sequence derived from the virus that induced the DGIs (TaMV). Because the WClMV replication cycle is limited to the cytoplasm, we conclude that this is the site of RNA degradation. The specific decrease of the TaMV CP RNA in DGIs was independent of whether the RNA was presented to the cell as a transgene transcript, homologous virus, or heterologous virus. Taken together, these observations suggest that a form of PTGS, resulting in sequence-specific degradation of RNA in the cytoplasm, is occurring in DGIs.

\section{Initiation of DGIs.}

There are few features that define the distribution of DGIs, apart from the observation that they occur only in leaves whose cells are actively dividing (Reid and Matthews 1966). Here, we assume that in DGIs, the initiating event occurs stochastically in single leaf cells during cell division. It is unclear which feature of dividing leaf cells might cause them to initiate DGI formation. One possibility is that the breakdown and reformation of the nuclear membrane could provide a window of opportunity for RNA sequences to enter the nucleus and trigger the production of the silencing signal. The $2 \mathrm{~b}$ inhibitor of PTGS initiation, encoded by Cucumber mosaic cucumovirus, localizes to the nucleus (Lucy et al. 2000). Thus, although the degradation event occurs in the cytoplasm, the initiation of PTGS may well be nuclear based. The initiation of DGIs in dividing leaf cells also may involve a component of preexisting PTGS, which signals from the infection process that occurs lower in the plant. A systemic PTGS signal appears to be generated in the initial stages of virus infection and spread throughout the plant via the phloem (Fagard and Vaucheret 2000). DGIs may be initiated in dividing cells in which the signal arrives before the infecting virus.

\section{Propagation of PTGS in DGIs.}

In $N$. benthamiana, DGIs are spherical in shape, which supports the idea that there is a cell-to-cell spread of the DGI silencing signal from one point of initiation. A diffusible signal originally was proposed to be involved in the spread of a DGI across cell layers (Atkinson and Matthews 1970). In light of this work and current knowledge of PTGS, this signal may be dsRNA. Interestingly, small dsRNAs of viral origin were detected in TYMV-infected tissue, which also produces DGIs (Bedbrook et al. 1974). These RNAs were not investigated further because of the paucity of molecular tools available at the time.

The inability of DGIs to spread and encompass an entire leaf or send a successful systemic silencing signal to new leaves is intriguing. Spread of the silencing signal from the originating cell may be limited to cell-to-cell movement. Thus, the size of the DGI may be limited by the number of cells to which the signal is distributed before it reaches a critical dilution end point. Alternatively, the size of a DGI may be restricted to cells that the silencing signal reaches ahead of the virus or prior to the translation of sufficient virus-encoded antisilencing proteins. In contrast to the situation in N. benthamiana, DGIs in tamarillo are frequently rectangular and bordered by veins (Fig. 1). This pattern suggests that there is some impedance of DGI spread. Moreover, there is a variation in the parameters for cell-to-cell and systemic movement of macromolecules in different plants (Lee et al. 2000).

The similarities between DGI and recovered tissue suggest that a single mechanism could underlie their initial formation. There are clear differences in the size and timing of DGIs and recovered tissues. DGIs are small and randomly located within individual leaves, whereas recovered tissue develops from the basal end of a leaf and progresses further along the lamina in each subsequent leaf. The sole genetic difference between plants that produce only DGIs and those that subsequently undergo recovery is the presence of a transgene in the latter. We suggest that the mechanism of induction of DGIs and recovery are similar, but the transgene influences the efficiency of propagation and maintenance of the subsequent silencing signal throughout the plant. The role of transgenes in propagation of silencing has been demonstrated previously in several systems (Fagard and Vaucheret 2000; Palauqui et al. 1997; Vaucheret et al. 1998). In recovered tissue in transgenic plants, the presence of preexisting homologous RNA in cells may affect the propagation of the silencing signal and its ability to move systemically. Once triggered, the silencing signal is able to move systemically upward in plants expressing the viral transgene, and this systemic signal spread results in recovery from viral infection.

\section{Conclusions.}

On the basis of the results reported here, we propose that DGIs are a part of the PTGS family of phenomena. This idea is consistent with previous suggestions that PTGS is part of the natural defense mechanism of plants against viral infection and that the infection process is the result of a complex interplay between host and pathogen. DGIs provide an experimental system for direct comparison between tissues that are highly successful at local viral defense and adjacent tissue vulnerable to virus infection. The difference between DGIs and recovered tissue also might allow for the screening of genes required to propagate the PTGS signal.

\section{MATERIALS AND METHODS}

\section{Plant material.}

Plants used in this work were $N$. benthamiana or transgenic $N$. benthamiana containing the TaMV CP. The PS26 line of transgenic plants was estimated to contain three or more independent insertions of the transgene by the segregation of kanamycin resistance in the $\mathrm{T}_{2}$ generation. The $\mathrm{T}_{4}$ generation of PS26 used in this work no longer gave kanamycinsusceptible plants, although the number or insertional arrangement of transgenes present has not been characterized. All seeds were germinated in seed trays and then transplanted into $20-\mathrm{cm}$ pots containing a commercially available potting mix that included slow-release fertilizer. Plants were grown in greenhouses with temperatures ranging from 14 to $18^{\circ} \mathrm{C}$ to optimize mosaic symptom expression (Johnson 1922). 


\section{Viruses and assessment of viral infection.}

A single isolate of TaMV was maintained in $N$. benthamiana and Nicotiana clevelandii. Inoculation of plants was performed by grinding an infected leaf in water and rubbing the sap onto one lower leaf of the target plant with carborundum as an abrasive. TaMV infection was assessed by the development of the characteristic mosaic on the leaves, which was first apparent at approximately 10 days postinoculation (dpi).

A WClMV vector $\left(7 \mathrm{~K}^{*}\right)$, donated by E. Balmori, contained a multiple cloning site inserted between the $7 \mathrm{~K}$ and $\mathrm{CP}$ genes, but with no additional viral promoters. WTam (also donated by E. Balmori) consisted of the $7 \mathrm{~K}^{*} \mathrm{WCIMV}$ vector (WCIMV accession no. X16636) with the TaMV CP coding region, bases 31 to 840 (numbering of Eagles et al. 1990), inserted into the $X h o \mathrm{I}$ site. For plant infection, DNA was linearized with SalI, and RNA was transcribed with SP6 RNA polymerase and mechanically inoculated onto the leaves. Where bulk amounts of the infectious WTam were required, leaves inoculated with RNA transcript were ground and used as inoculum at 3 dpi.

\section{RT-PCR for virus detection.}

RT-PCR was performed with the Superscript One-Step RTPCR System (Life Technologies, Rockville, MD, U.S.A.). To determine infection, $0.03 \mathrm{~g}$ of leaf tissue was ground in $50 \mu \mathrm{L}$ of $50 \mathrm{mM}$ phosphate buffer and $0.5 \mu \mathrm{L}$ of the resulting supernatant used as template in the RT-PCR. To compare the viruses in DGIs and adjacent yellow tissue, total RNA was isolated from tissue (Trizol, Life Technologies), fivefold serially diluted seven times, and used as template $(0.5 \mu \mathrm{L})$ in the 20 $\mu \mathrm{L}$ RT-PCR. When multiple pairs of primers were used for analysis of an RNA template, reactions were carried out in separate tubes to avoid depletion of reagents by amplification of the more abundant sequences. Standardization of the reactions was performed by comparison to the RT-PCR product of ssRuBP. For each pair of DGI-infected samples, all reactions were performed at the same time in the same thermal cycler. The ssRuBP primers were designed across an intron so that any amplification from DNA would be detected (Table 1).

\section{Northern analysis.}

Total RNA $(5 \mu \mathrm{g})$ was separated by electrophoresis through an agarose gel containing formaldehyde and transferred to a Hybond N+ nylon membrane (Amersham Pharmacia Biotech, Little Chalfont, Buckinghamshire, U.K.) by capillary blotting with $10 \times \mathrm{SSC}(1 \times \mathrm{SSC}$ is $0.15 \mathrm{M} \mathrm{NaCl}$ plus $0.015 \mathrm{M}$ sodium citrate). The membrane was prehybridized for $4 \mathrm{~h}$ and hybrid- ized for $16 \mathrm{~h}$ in buffer at $65^{\circ} \mathrm{C}$ (Church and Gilbert 1984), with a ${ }^{32} \mathrm{P}$-labeled DNA probe (Rediprime II, Amersham Pharmacia Biotech). After hybridization, the membrane was washed twice at room temperature for $2 \mathrm{~min}$ in $2 \times \mathrm{SSC}, 0.1 \%$ sodium dodecyl sulfate (SDS), and twice for $30 \mathrm{~min}$ in $1 \times$ SSC, $0.1 \%$ SDS, at $65^{\circ} \mathrm{C}$. Detection of hybridized fragments was performed by exposure to Kodak XK-1 film (Windsor, CO, U.S.A.) at $-80^{\circ} \mathrm{C}$.

\section{Microscopy.}

Pieces of leaf tissue $(2 \times 5 \mathrm{~mm})$ were cut at right angles to, and incorporating the bizonal layer. The tissue was fixed in $2.5 \%$ glutaraldehyde in $0.1 \mathrm{M}$ phosphate buffer, $\mathrm{pH} 7.2$, under a vacuum for $1 \mathrm{~h}$. Tissue pieces were washed in buffer, postfixed in $1 \%$ osmium tetroxide for $1 \mathrm{~h}$, washed in buffer, dehydrated in an ethanol series, and embedded in Spurrs resin. Sections of $1 \mu \mathrm{m}$ thick were dried onto slides and stained with toluidine blue, which stains cell walls darker in healthy tissue than it does in infected tissue. These sections were used to characterize the general anatomy of the leaf by light microscopy. To create a detailed map of the leaf anatomy and to detect viral particles, two 100-nm thick sections from both sides of the original 1- $\mu \mathrm{m}$ section were placed on Formvar-coated copper grids and stained with $1 \%$ aqueous uranyl acetate and lead citrate (Roland 1978). Sections were observed in a JEOL JEM-1200EXII electron microscope (Peabody, MA, U.S.A.) operating at $80 \mathrm{kV}$, the presence or absence of viral particles and inclusion bodies were analyzed, and the data transferred to the overall cell map created from the $1-\mu \mathrm{m}$ section.

\section{ACKNOWLEDGMENTS}

We thank D. Beck, E. Balmori, and K. Plummer for valuable discussions; D. Beck, K. Snowden, and B. Janssen for critical reading of the manuscript; and E. Balmori for his gift of the WTam clone. R. M. MacDiarmid has previously published as R. M. Eagles. This work was supported by Marsden Fund research grants C06540 and HRT806 to R. L. Forster and R. M. MacDiarmid, respectively.

\section{LITERATURE CITED}

Allard, H. A. 1914. A review of the investigation of the mosaic disease of tobacco, together with a bibliography of the more important contributions. Bull. Torrey Bot. Club 41:435-458.

Atkinson, P. H., and Matthews, R. E. F. 1970. On the origin of dark green tissue in tobacco leaves infected with tobacco mosaic virus. Virology 40:344-356.

Baulcombe, D. 1999. Viruses and gene silencing in plants. Arch. Virol. Suppl. 15:189-201.

Beck, D. L., Forster, R. L., Bevan, M. W., Boxen, K. A., and Lowe, S. C. 1990. Infectious transcripts and nucleotide sequence of cloned cDNA

Table 1. Primers used for reverse-transcription-polymerase chain reaction

\begin{tabular}{|c|c|c|}
\hline Target sequence & Primer sequences $^{\mathrm{a}}$ & Expected product size (bp) \\
\hline ssRuBP & $\begin{array}{l}\text { F: GCTTCCTCAGTTCTTTCCTC } \\
\text { R: AATTGCTCCTGGCTCAAATC }\end{array}$ & 244 \\
\hline Genomic Tamarillo mosaic potyvirus ( $5^{\prime}$ virus region) & $\begin{array}{l}\text { F: AGAGCCAGTGGAGAAGAAG } \\
\text { R: AGCACTCGTAGCAGGATAG }\end{array}$ & 400 \\
\hline White clover mosaic potexvirus (WCIMV) and $\mathrm{WTam}^{\mathrm{b}}$ & $\begin{array}{l}\text { F: GCTTCTGTTGAAATCTCAGGTTGC } \\
\text { R: ATGTCTGTCAAGGATGGAGGAGTG }\end{array}$ & $\begin{array}{l}149 \text { (WClMV) } \\
1,034 \text { (WTam) }\end{array}$ \\
\hline
\end{tabular}

${ }^{\mathrm{a}} \mathrm{F}=$ forward $\mathrm{R}=$ reverse.

b WTam is a WClMV-based construct. 
of the potexvirus white clover mosaic virus. Virology 177:152-158.

Bedbrook, J., Douglas, J., and Matthews, R. E. 1974. Evidence for TYMV-induced RNA and DNA synthesis in the nuclear fraction from infected Chinese cabbage leaves. Virology 58:334-344.

Chalcroft, J., and Matthews, R. E. F. 1966. Cytological changes induced by turnip yellow mosaic virus in Chinese cabbage leaves. Virology 28:555-562.

Church, G. M., and Gilbert, W. 1984. Genomic sequencing. Proc. Natl. Acad. Sci. USA 81:1991-1995.

Dickson, B. T. 1922. Studies concerning mosaic diseases. Tech. Bull. 2 MacDonald Coll. McGill Univ.

Dougherty, W. G., Carrington, J. C., Cary, S. M., and Parks, T. D. 1988. Biochemical and mutational analysis of a plant virus polyprotein cleavage site. EMBO J. 7:1281-1287.

Dougherty, W. G., Lindbo, J. A., Smith, H. A., Parks, T. D., Swaney, S., and Proebsting, W. M. 1994. RNA-mediated virus resistance in transgenic plants: exploitation of a cellular pathway possibly involved in RNA degradation. Mol. Plant-Microbe Interact. 7:544-552.

Eagles, R. M., Gardner, R. C., and Forster, R. L. 1990. Nucleotide sequence of the tamarillo mosaic virus coat protein gene. Nucleic Acids Res. 18:7166.

Fagard, M., and Vaucheret, H. 2000 (Trans)gene silencing in plants: How many mechanisms? Annu. Rev. Plant Physiol. Plant Mol. Biol. 51:167-194.

Fagard, M., Boutet, S., Morel, J. B., Bellini, C., and Vaucheret, H. 2000. AGO1, QDE-2, and RDE-1 are related proteins required for posttranscriptional gene silencing in plants, quelling in fungi, and RNA interference in animals. Proc. Natl. Acad. Sci. USA 97:11650-11654.

Fulton, R. W. 1951. Superinfection by strains of tobacco mosaic virus. Phytopathology 41:579-592.

Goldstein, B. 1926. A cytological study of the leaves and growing points of healthy and mosaic diseased tobacco plants. Bull. Torrey Bot. Club 53:499-599.

Guo, H. S., and Garcia, J. A. 1997. Delayed resistance to plum pox potyvirus mediated by a mutated RNA replicase gene: Involvement of a gene-silencing mechanism. Mol. Plant-Microbe Interact. 10:160170.

Holmes, F. O. 1928. Accuracy in quantitative work with tobacco mosaic virus. Bot. Gaz. 86:66-81.

Iwanowski, D. 1903. Über die mosaikkrankheit der tabakspflanzen. Z. Pflanzenkr. 13:1-41.

Johnson, J. 1922. The relation of air temperature to the mosaic disease of potatoes and other plants. Phytopathology 12:438-440.

Jorgensen, R. A., Atkinson, R. G., Forster, R. L., and Lucas, W. J. 1998. An RNA-based information superhighway in plants. Science (Wash. D.C.) 279:1486-1487

Ketting, R. F., Haverkamp, T. H., Van Luenen, H. G., and Plasterk, R. H. 1999. Mut-7 of C. elegans, required for transposon silencing and RNA interference, is a homologue of Werner syndrome helicase and RNase D. Cell 99:133-141.

Lee, J. Y., Yoo, B. C., and Lucas, W. J. 2000. Parallels between nuclearpore and plasmodesmal trafficking of information molecules. Planta (Berl.) 210:177-187.

Lindbo, J. A., and Dougherty, W. G. 1992. Untranslatable transcripts of the tobacco etch virus coat protein gene sequence can interfere with tobacco etch virus replication in transgenic plants and protoplasts. Virology 189:725-733.

Lucy, A. P., Guo, H. S., Li, W. X., and Ding, S. W. 2000. Suppression of post-transcriptional gene silencing by a plant viral protein localized in the nucleus. EMBO J. 19:1672-1680.

Matthews, R. E. F. 1991. Plant Virology. Academic Press, San Diego.

McBride, K. E., and Summerfelt, K. R. 1990. Improved binary vectors for Agrobacterium-mediated plant transformation. Plant Mol. Biol. 14:269-276.

Meyer, P. 1996. Repeat-induced gene silencing: Common mechanisms in plants and fungi. Biol. Chem. Hoppe-Seyler 377:87-95.

Mossop, D. W. 1977. Isolation, purification and properties of tamarillo mosaic virus, a member of the potato virus Y group. N. Z. J. Agric. Res. 20:535-541.

Napoli, C., Lemieux, C., and Jorgensen, R. A. 1990. Introduction of a chimeric chalcone synthase gene into petunia results in reversible cosuppression of homologous genes in trans. Plant Cell 2:279-289.

Pal-Bhadra, M., Bhadra, U., and Birchler, J. A. 1997. Cosuppression in Drosophila: Gene silencing of alcohol dehydrogenase by white-Adh transgenes is polycomb dependent. Cell 90:479-490.

Palauqui, J. C., Elmayan, T., Pollien, J. M., and Vaucheret, H. 1997. Systemic acquired silencing: Transgene-specific post-transcriptional silencing is transmitted by grafting from silenced stocks to nonsilenced scions. EMBO J. 16:4738-4745

Pang, S. Z., Jan, F. J., Tricoli, D. M., Russell, P. F., Carney, K. J., Hu, J. S., Fuchs, M., Quemada, H. D., and Gonsalves, D. 2000. Resistance to squash mosaic comovirus in transgenic squash plants expressing its coat protein genes. Mol. Breed. 6:87-93.

Rajamäki, M., Merits, A., Rabenstein, F., Andrejeva, J., Paulin, L., Kekarainen, T., Kreuze, J. F., Forster, R. L. S., and Valkonen, J. P. T. 1998. Biological, serological, and molecular differences among isolates of potato A potyvirus. Phytopathology 88:311-321.

Ratcliff, F., Harrison, B. D,. and Baulcombe, D. C. 1997. A similarity between viral defense and gene silencing in plants. Science (Wash D.C.) 276:1558-1560

Reid, M. S., and Matthews, R. E. F. 1966. On the origin of the mosaic induced by turnip yellow mosaic virus. Virology 28:563-570.

Roland, J. C. 1978. General preparation and staining of thin sections. Pages 1-62 in: Electron microscopy and cytochemistry of plant cells. J. L. Hall, ed. Elsevier-North, Amsterdam.

Ruiz, F., Vayssie, L., Klotz, C., Sperling, L., and Madeddu, L. 1998a. Homology-dependent gene silencing in Paramecium. Mol. Biol. Cell 9:931-943

Ruiz, M. T., Voinnet, O., and Baulcombe, D. C. 1998b. Initiation and maintenance of virus-induced gene silencing. Plant Cell 10:937-946.

Tuschl, T., Zamore, P. D., Lehmann, R., Bartel, D. P., and Sharp, P. A 1999. Targeted mRNA degradation by double-stranded RNA in vitro. Genes Dev. 13:3191-3197.

Van der Krol, A. R., Mur, L. A., Beld, M., Mol, J. N., and Stuitje, A. R. 1990. Flavonoid genes in petunia: Addition of a limited number of gene copies may lead to a suppression of gene expression. Plant Cell 2:291-299.

Vaucheret, H., Beclin, C., Elmayan, T., Feuerbach, F., Godon, C., Morel, J. B., Mourrain, P., Palauqui, J. C., and Vernhettes, S. 1998. Transgene-induced gene silencing in plants. Plant J. 16:651-659.

Waterhouse, P. M., Smith, N. A., and Wang, M. B. 1999. Virus resistance and gene silencing: Killing the messenger. Trends Plant Sci. 4:452457.

Wianny, F., and Zernicka-Goetz, M. 2000. Specific interference with gene function by double-stranded RNA in early mouse development. Nat. Cell Biol. 2:70-75. 